\title{
Children with autism spectrum disorders
}

\author{
Comentado por: Fernanda Dreux Miranda Fernandes ${ }^{1}$
}

Bernard-Opitz, V. Children with autism spectrum disorders: A structured teaching and experienced-based program. Austin, Texas: Pro-Ed; 2007.

Este livro é apresentado como um programa estruturado e baseado em experiências para terapeutas, professores e pais. Ele pode ser visto como mais um dos inúmeros programas disponíveis nos Estados Unidos para treinamento e terapia de crianças do espectro autístico, muitos dos quais propõem a colaboração dos pais. A autora, psicóloga com PhD em Psicologia Clínica e Ciências do Comportamento, tem extensa experiência com essa população em diversos centros especializados e isso é o primeiro diferencial desta publicação, num conjunto em que a maioria do material disponível é baseado em propostas frágeis ou incipientes.

A apresentação da obra comenta que os últimos 35 anos testemunharam um grande desenvolvimento no conhecimento a respeito dos distúrbios do espectro autístico (DEA) e seu tratamento. A partir da descrição da síndrome autística sua incidência aumentou significativamente nos últimos anos. Em 1968 a taxa estimada era de quatro crianças autistas em 10.000, mas estudos recentes indicam que em torno do ano 2000 essa taxa tinha aumentado mais de 200\%, chegando a mais de uma criança autista a cada 1000 crianças. Se esse aumento deve-se a critérios diagnósticos mais sistemáticos ou se os transtornos autísticos estão mesmo se tornando mais freqüientes ainda é objeto de discussão.

Este guia, dirigido aos pais e terapeutas, aborda principalmente o que são os distúrbios do espectro autístico (DEA) e formas de tratamento. A autora afirma que crianças com DEA apresentam uma ampla variedade de desordens comportamentais, motivacionais e de aprendizagem, que não são abordados satisfatoriamente em processos terapêuticos comuns ou por métodos lineares com proposição de aplicação universal. Argumenta que a terapia bem sucedida deve ser parte de um processo estruturado, centrado nos problemas, interesses e habilidades individuais de cada criança. Os exemplos apresentados, segundo a autora, demonstram que a observação diagnóstica e a intervenção são complementares.

A publicação tem apresentação didática e linguagem simples, abordando de forma direta conceitos e propostas específicas. Apresenta, em seu início, uma perspectiva simplificada do diagnóstico dentro do espectro autístico, sugerindo itens de observação e critérios de avaliação para que a suspeita de autismo seja levantada e as primeiras oportunidades de verificação ou exclusão sejam consideradas. Embora haja uma intenção nítida de objetividade e de aplicabilidade dos

(1) Livre-Docente; Professora do Curso de Fonoaudiologia do Departamento de Fisioterapia, Fonoaudiologia e Terapia Ocupacional da Faculdade de Medicina da Universidade de São Paulo - USP - São Paulo (SP), Brasil.

Endereço para correspondência: Fernanda Dreux Miranda Fernandes. R. Cipotânea, 51, Cidade Universitária, São Paulo - SP, CEP 05360-160. E-mail: fernandadreux@usp.br conceitos e propostas, a simplificação parece excessiva e cria o risco de atribuição exagerada do diagnóstico (ou suspeita) de autismo. A descrição de casos clínicos facilita a compreensão do tema pelo leitor leigo.

Na introdução à questão das abordagens terapêuticas a autora aborda criticamente as propostas de intervenção propostas como soluções aplicáveis a todos os indivíduos com autismo, comentando a ausência de dados objetivos que comprovassem essa eficiência. A heterogeneidade dos grupos de indivíduos autistas, que requerem avaliações complexas e não respostas simples e exige escolhas que devem ser compartilhadas com as famílias.

A seguir são exemplificadas algumas das alternativas, como a análise de comportamento aplicada (ABA), em que são aplicados os princípios da análise do comportamento na determinação de procedimentos sistematicamente controlados, destinados a ampliar a quantidade de comportamentos socialmente significativos. A partir dessa perspectiva, um "paradigma de fala natural" foi proposto; ele enfatiza iniciativas de comunicação pela criança e usa reforçadores naturais.

Abordagens que incluem as de aprendizagem estruturada, como o TEACCH e outras propostas que utilizam o apoio de sistemas de comunicação visual, são mencionadas superficialmente nessa introdução.

A perspectiva sócio-pragmatica é descrita como uma proposta de intervenção baseada na experiência da criança, atividades e relações sociais. As contribuições da Linguística, especialmente no que diz respeito ao exercício dos diferentes papeis na interlocução, são enfatizadas. Situações baseadas em experiências e atividades práticas estão envolvidas em uma abordagem naturalística. As premissas principais são as de que as vivencias praticas e a boa interação com o terapeuta são fundamentais para a aprendizagem.

As práticas baseadas em evidências dizem respeito à possibilidade de verificação dos resultados dos processos de intervenção. Evidentemente existem diferentes níveis de evidências, que vão desde estudos individuais até estudos clínicos com grupos-controle. Pais e professores devem estar atentos ao tipo de evidência de resultados disponíveis em relação a cada diferente proposta, para que possam fazer opções informadas.

A seguir a autora apresenta um método desenvolvido por ela desde 1988, o STEP (Structured Teaching for Exceptional Pupils), que já foi adaptado para aplicação em diversos países e que vem sendo modificado ao longo do tempo.

Os princípios do método incluem: pequenas etapas de progresso; iniciativa inicial do terapeuta; uso de estímulos e reforços específicos para cada criança; tarefas de repetição; pequenas unidades de tempo; uso de vários canais para estímulo e 
resposta; acompanhamento sistemático da evolução; ênfase em aprendizagem por experiência; ensino incidental; oportunidades de experiências relevantes; aproveitamento das iniciativas espontâneas da criança; interrupção de seqüências de rituais; uso de apoio visual e atividades de apoio estruturadas.

A autora apresenta sugestões de manejo das questões comportamentais, baseadas no manejo ambiental e dos fatores que, segundo ela, eliciam os comportamentos desestruturantes (birras, agressões, falta de cooperação, auto-agressão, ecolalia e comportamentos compulsivos). Esses fatores incluiriam pedidos de atenção, evitação de exigências e estimulação sensorial excessiva ou inadequada. São apresentados alguns exemplos de situações cotidianas potencialmente eliciadoras de comportamentos inadequados e manejos alternativos para essas situações. A autora enfatiza sistematicamente a necessidade de uma análise individualizada da criança, sua família e as situações experienciadas.

Segundo a autora, existem varias alternativas para reforçar comportamentos adequados e novas aquisições. Há uma hierarquia nesses reforços disponíveis, que é iniciada com reforços materiais (como brinquedos, alimentos e bebidas), evolui para atividades (passeios, cantar, usar o computador ou o videogame), a seguir para reforços simbólicos (fichas, graus, medalhas, títulos) e finalmente para reforços sociais (elogios, reconhecimento, jogos interativos, abraços).

As atividades de terapia baseada na experiência geralmente ocorrem em ambientes naturais, com materiais simples, referentes aos objetivos da terapia, oferecidos à criança e com a participação constante do terapeuta. $\mathrm{O}$ material e a situação devem variar de acordo com a idade e os interesses de cada criança e com os objetivos da terapia. A autora comenta a dificuldade da primeira sessão terapêutica com uma criança autista e revela que ela e seus colegas geralmente pedem que os pais mostrem, por 15 minutos, como eles brincam com seu filho. Mas também comenta que pode ser necessário limitar os movimentos da criança para evitar que ela corra para longe.

A avaliação das habilidades da criança incluiria questões chave para observação de aspectos como o contato ocular e a atenção compartilhada:

- a criança responde com atenção ou contato ocular para ruídos, movimento, ordens ou chamado?

- para que a criança precisa de ajuda (abrir um frasco, pegar uma bola)?

- que series de ações são motivadoras para a criança (comer, balançar)?

- em que situações a criança demonstra alegria, curiosidade, interesse, retração ou ansiedade?

- a criança estabelece contato ocular ou acompanha o olhar do outro espontaneamente?

- que tipo de ocorrência provoca contato ocular espontâneo?

- a criança consegue atrair a atenção do outro?

São apresentadas sugestões de atividades específicas para abordar cada uma dessas habilidades.

Outras áreas de habilidades abordadas são: pareamento e categorização, imitação, compreensão da linguagem, iniciativa de comunicação, expansão da linguagem, jogo simbólico, comportamento social e independência. Para cada uma dessas áreas são apresentadas sugestões de atividades em diversos níveis de complexidade, exemplos de casos clínicos e quadros e esquemas para acompanhamento da evolução.

A importância de um programa a ser desenvolvido pelos pais é enfatizada como um elemento fundamental para o progresso. Mas a autora admite que nem todas as pessoas conseguem atuar de forma produtiva com essas crianças. Muitas vezes as questões de trabalho dos pais inviabilizam sua maior dedicação. Nesses casos a autora sugere a viabilização de programas de tutoria realizados na residência e/ou na escola.

Trata-se de uma proposta abrangente de enfocar uma questão muito complexa: o delineamento de objetivos e procedimentos de intervenção destinados a uma população com uma variação muito grande de manifestações.

Embora possa haver argumentação e discordância em relação a muitos dos pontos abordados e haja, sem dúvida, a necessidade de cautela em relação à aplicação imediata dos princípios apresentados. A maior parte das sugestões educacionais baseadas nas teorias do comportamento pode encontrar reflexo nas práticas educacionais comuns e já tiveram sua utilidade comprovada inúmeras vezes. Entretanto, o controle comportamental estrito pode gerar ume perspectiva reducionista das relações interpessoais. A autora resolve essa questão de forma pragmática: privilegia a aplicabilidade clínica terapêutica e não a consistência teórica. Assim, as orientações apresentadas são mais praticamente úteis do que cientificamente fundamentadas.

Essa opção pode ser feita por poucos. Ela exige grande bagagem científica e extensa prática profissional, de forma que as duas funcionem como contrapontos. O resultado são orientações que, embora possam ser discutidas, são geralmente úteis para profissionais que atuam com essa população.

$\mathrm{O}$ ponto que distingue essa obra das outras propostas de manuais e programas, e que torna esse material efetivamente novo, é a ênfase na abordagem individualizada, baseada no perfil de habilidades e dificuldades de cada criança e nas alternativas ambientais e familiares disponíveis para cada uma delas.

A noção de que essa é a alternativa que vem proporcionando os melhores resultados terapêuticos com crianças do espectro autístico vem sendo discutida na literatura há aproximadamente uma década. Entretanto, a maioria dos manuais de orientação terapêutica e educacional continua a propor programas estritos a serem aplicados a todas as crianças (eventualmente com alguma adaptação relativa à idade).

A existência de um material estruturado, proposto por uma autora reconhecida, que aborda questões como a individualização dos processos terapêuticos, a importância das experiências significativas e dos contextos naturais e a necessidade de consideração a respeito das possibilidades dos pais para desenvolver atividades terapêuticas no ambiente doméstico é uma ótima notícia para uma área tão instigante.

A ênfase na necessidade de verificação sistemática da evolução terapêutica reforça a tendência atual de valorização da prática baseada em evidência, que proporciona informações importantes a pais e professores e, principalmente, elementos importantes para eventuais ajustes no processo de intervenção.

Embora as opções terapêuticas e educacionais para crianças autistas nos Estados Unidos e no Brasil sejam muito diferentes, as proposições apresentadas nesse livro são, em sua maioria, muito úteis para profissionais brasileiros também. 